SIMPLIFYING THE COMPLEX 
This page intentionally left blank 


\title{
SIMPLIFYING THE COMPLEX
}

A Guide to Transition and Activation Planning for Healthcare Construction Projects

\author{
BY \\ YELLOW BRICK CONSULTING, INC. \\ EDITED BY \\ KELLY GUZMAN \\ AUTHORED BY \\ ANN AHMADI, ALISON BRODERS, \\ CHRISTINA OLIVARRIA, JEFF AGNER, \\ LYNN AGUILERA AND \\ KATHY STEVENSON
}

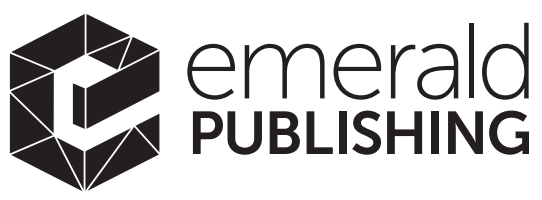

United Kingdom - North America - Japan India - Malaysia - China 
Emerald Publishing Limited

Howard House, Wagon Lane, Bingley BD16 1WA, UK

First edition 2020

(C) 2020 Yellow Brick Consulting

Published under exclusive licence by Emerald Publishing Limited.

Reprints and permissions service

Contact: permissions@emeraldinsight.com

No part of this book may be reproduced, stored in a retrieval system, transmitted in any form or by any means electronic, mechanical, photocopying, recording or otherwise without either the prior written permission of the publisher or a licence permitting restricted copying issued in the UK by The Copyright Licensing Agency and in the USA by The Copyright Clearance Center. Any opinions expressed in the chapters are those of the authors. Whilst Emerald makes every effort to ensure the quality and accuracy of its content, Emerald makes no representation implied or otherwise, as to the chapters' suitability and application and disclaims any warranties, express or implied, to their use.

\section{British Library Cataloguing in Publication Data}

A catalogue record for this book is available from the British Library

ISBN: 978-1-83867-972-9 (Print)

ISBN: 978-1-83867-969-9 (Online)

ISBN: 978-1-83867-971-2 (Epub)

\section{ISOQAR certified}

Management System

awarded to Emerald

for adherence to

Environmental

standard

ISOQAR ISO 14001:2004

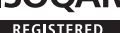

Certificate Number 1985

ISO 14001

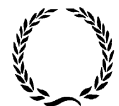

INVESTOR IN PEOPLE 


\section{TABLE OF CONTENTS}

About the Authors vii

Acknowledgments $\quad$ ix

What You Need to Know to Open Your Healthcare Facility xi

1. Project Kickoff and Getting Started 1

Kelly Guzman

2. Tools for Success 25

Kelly Guzman and Christina Olivarria

3. New Facility Transition and Activation Budget Planning 47 Jeff Agner

4. Building Readiness 67

Kathy Stevenson

5. People Readiness 77

Lynn Aguilera

6. Reflections and Conclusions 93

Kelly Guzman

Glossary 95

Index 99 
This page intentionally left blank 


\section{ABOUT THE AUTHORS}

Kelly Guzman, MN, RN, is the Founder and President of Yellow Brick Consulting, Inc. with more than 30 years of healthcare experience and has helped pioneer the path for the Transition and Activation Planning industry. Her career started as a pediatric and ER nurse and progressed to hospital administrative positions before finding her passion for Transition and Activation Planning while working at UCLA on the new Ronald Reagan Medical Center. She has worked in the Transition and Activation Planning field for over 15 years and helped activate over 40 new facilities across North America. Kelly has a master's degree focused in Nursing Administration from UCLA.

Lynn Aguilera, DM/IST, MSNEd, RN, CPN, CPHIMS, PMP, is a Project Specialist at Yellow Brick with more than 25 years of healthcare industry experience in hospital operations and Transition and Activation Planning. Lynn is the Administrative Director of Strategic Space Planning and Transition Strategy at Lucile Packard Children's Hospital Stanford and the lead author of "Using Interdisciplinary Dress Rehearsal Events to Ensure Staff Readiness When Opening a New Healthcare Facility" published by Health Environments \& Research Design Journal (HERD) in July 2019.

Jeff Agner, MPH, BA, is the Director for Transition and Activation Planning at Yellow Brick Consulting and has 14 years of healthcare Transition and Activation Planning experience. Jeff is responsible for the execution of Yellow Brick's strategic initiatives and Transition and Activation Planning process implementation. 
Ann Ahmadi, MBA, RN, is the Director of Innovation at Yellow Brick with more than 30 years of healthcare industry experience in hospital operations and Transition and Activation Planning. Ann is responsible for the development of the automated systems used to create Dress Rehearsal scenarios and to track Task Lists within the transition project.

Kathy Stevenson, BSN, RN, is the Director of Operations and Strategy at Yellow Brick with more than 30 years of industry experience in hospital operations and Transition and Activation Planning. Kathy is responsible for the strategic direction as well as day-to-day operations at Yellow Brick. Kathy is an expert in the Transition and Activation Planning process, Dress Rehearsal and Move execution. Kathy has been published multiple times and one of her most cited articles is "Reunification: Keeping Families Together in Crisis" published in the Journal of Trauma Injury, Infection and Critical Care in August 2009.

Ali Broders, BA, PMP, is a Project Manager at Yellow Brick with more than nine years of industry experience in healthcare Transition and Activation planning. Ali has led more than 20 projects and has extensive background in healthcare operations planning and regulatory compliance.

Christina Olivarria, MSPM, BS, is the Communications Manager and Project Manager at Yellow Brick with six years of industry experience in healthcare Transition and Activation Planning. Christina is responsible for all corporate communications and marketing as well as the management of healthcare projects. 


\section{ACKNOWLEDGMENTS}

This guide is a labor of love and has been made possible by a dedicated group of healthcare project managers who wanted to share their collective experience with Transitioning and Activation Planning in healthcare facility projects. Special acknowledgment goes to Lynn Aguilera, Jeff Agner, MaryAlice Agner, Ann Ahmadi, Ali Broders, Erica Dickey, Melissa Johnston, Donna McNeeseSmith, Christina Olivarria, Kim Roberts, Kathy Stevenson, and the entire Yellow Brick Consulting team who have committed their time to share their perspective, experience, and expertise with healthcare leaders. 
This page intentionally left blank 


\section{WHAT YOU NEED TO KNOW TO OPEN YOUR HEALTHCARE FACILITY}

\section{THE PURPOSE OF THIS GUIDE}

Simplifying the Complex: A Guide to Transition and Activation Planning for Healthcare Construction Projects was written to provide the reader with an overview of the fundamentals of the Transition and Activation Planning process. We started with a blank canvas, a love for healthcare, a passion for project work, and a commitment to finding best practices for Transition and Activation Planning for new healthcare facilities. Our team has worked in healthcare for more than 30 years and in the Transition and Activation Planning field for more than 15 years.

In our experience with Transition and Activation Planning projects of all sizes and scopes, we find that many healthcare leaders do not have the experience or internal expertise to lead and manage a Transition and Activation Planning project. While the Transition and Activation of a unit or a few departments could be absorbed into a department leader's day-to-day responsibilities, the Transition and Activation of a new tower or facility requires dedicated resources and an experienced team to guide these efforts. This guide provides the framework needed to navigate a Transition and Activation project, with a roadmap and tools to plan and implement a project of any size.

The transition to a new facility or department is not as simple as switching the lights off in one facility and turning them on in 
another. Hospitals operate 24/7 and do not have the ability to stop operations or patient care, in order to move into a new facility. A project of this complexity calls for an experienced team that possesses industry knowledge and can share tools and best practices. The right team is an important part of the foundation for an organization's successful journey in the Transition and Activation of a new facility.

In our industry we frequently hear concerns such as, "I don't know what I don't know" and "I've never done something like this before. Where do I begin?"

\section{HOW TO USE THIS GUIDE}

You may be reading this guide because you are leading a Transition and Activation Planning project and need a resource to guide you through the process, or as an assignment for school or work.

This guide was developed to use as a resource throughout your Transition and Activation Planning journey. Each chapter can be read independently, or as part of the overall guide. This introduction will outline how to navigate through this guide and the subsequent chapters and tips to get the best use from each chapter.

\section{CHAPTER ORGANIZATION}

The chapters are organized using the following format:

- Chapter Objectives

- Introduction of the Subject

- Content

- Summary of Key Points 


\section{MARGIN ASSISTS}

The following icons are used throughout the guide to assist with learning and referencing the content:

Sey point - Important concept

\section{ESTABLISHING A TRANSITION AND ACTIVATION PLANNING BASELINE}

This guide will provide recommendations for a Transition and Activation Planning framework that is scalable to a project of any size. In an effort to provide context and a standard throughout the guide, the recommendations are based on the following criteria:

- 150-200-bed community hospital

- All services and patients moving to the new facility

- 24-month time frame

The Transition and Activation Planning framework, processes, and recommendations are scalable and have been used on projects of all sizes, including critical access hospitals, large academic 
medical centers, and ambulatory centers. The recommendations in this guide are based on the 150-200-bed community hospital described earlier; therefore, when implementing the tools, an evaluation should be complete to ensure the content, level of detail, participants, and schedule are appropriate for the given project. Not all tools are applicable or required for every project, so it is important to assess and apply what makes practical sense for your project and organization. A larger and more complex project will require additional time, effort, and resources, and the planning efforts should be adjusted accordingly.

\section{Why This Is Important}

Capital projects are strategic initiatives that are high-risk and problem-prone due to the various moving pieces and the nature of construction projects. Much thought is put into the design and construction process and the required resources (hard costs) to manage them. Equal attention and resources are needed for the Transition and Activation Planning of the building (soft costs). The management of a healthcare construction project presents unique challenges. These projects include the building of facilities that oftentimes cannot stop operations to transition and move to a new facility. Developing and implementing detailed plans for these projects must account for parallel operations with shared staff and contingency plans for high-risk situations during the move.

Establishing a consistent process is critical to the success of any project or workstream. A solid framework will help the team responsible for managing the Transition and Activation Planning project to explain, predict, and plan the work required to implement the Transition and Activation Planning workplan. This guide will provide the process and framework needed to manage the Transition and Activation of a new healthcare facility.

\section{Defining Transition and Activation Planning}

Definitions are found throughout the guide and in the glossary.

Transition and Activation Planning is the process of planning, implementing, and evaluating the physical (Building 
Readiness) and Human Resource (People Readiness) components that support the opening of a new clinical space or building. The plan supports the organization's goal of taking the building from design and construction to a live and operational facility.

\title{
Transition and Activation Planning Framework
}

\begin{abstract}
III Our team has developed a Transition and Activation Planning framework using principles from the Project Management Book of Knowledge (PMBOK) and the nursing model of "Assess, Plan, Implement, and Evaluate." Together, these methods have proven to be successful approaches when developing a Transition and Activation plan and can be scaled to support projects of all sizes. By developing a framework with recommended timelines, resources, and outputs, the owner has a consistent method to manage the process.

Some unique characteristics in the development of the framework for the Transition and Activation Plan include the following assumptions:
\end{abstract}

- The responsibility for the leadership and the oversight of the Transition and Activation Planning efforts are commonly delegated to the Chief Operating Officer or the Vice President of Facilities and Design.

- The work associated with the Transition and Activation Planning is typically in addition to their already busy schedule and workload.

- Not all hospital leaders are trained or skilled in project management.

- Missing a deadline in a major capital project causes significant financial impacts to the organization.

- An easy-to-use guide with a roadmap and plan to implement and manage a Transition and Activation project is essential.

These assumptions are the basis in the development of the framework and the recommendations presented in this guide and should be considered when developing the overall project approach, a timeline, and the resources required to manage a project. 


\title{
Transition and Activation Planning: Where Does it Fit in on the New Facility Project Life Cycle?
}

\begin{abstract}
III Understanding the continuum of a new facility capital project and its life cycle are important to the understanding of the scope and resources required for a Transition and Activation Planning project. Some Transition and Activation Planning activities begin during the Planning Phase of a major capital project. The traditional architectural and construction phases and their relationship to Transition and Activation Planning activities are highlighted in the schematic below (Fig. 1).
\end{abstract}

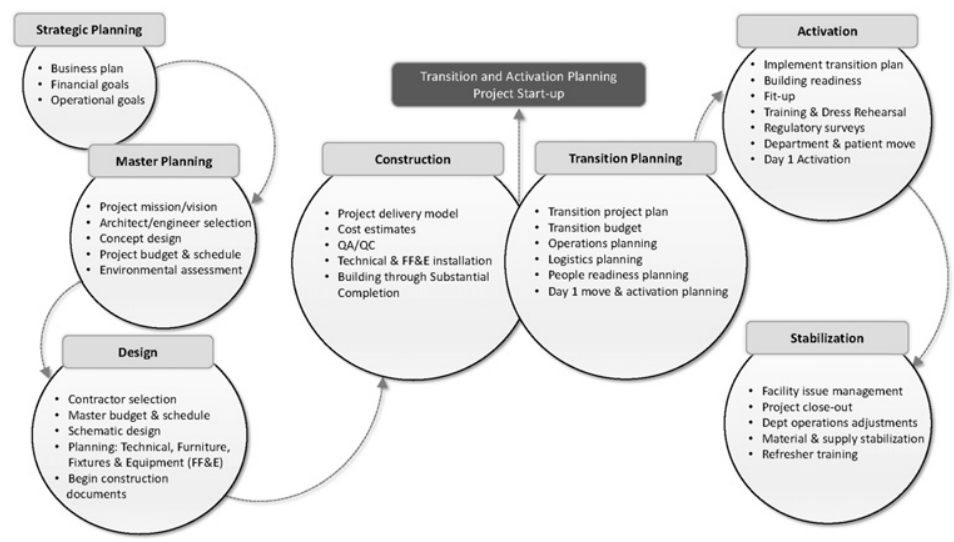

Fig. 1. New facility project life cycle.

\section{The Planning Phase: Strategic Planning and Master Planning}

\begin{abstract}
0 This phase of the project can occur anywhere from 3 to 10 years before Day 1 Activation in the new facility. It includes the development of the strategic plan, master plan, environmental assessment, and the business analysis. The planning phase focuses on understanding the needs and goals of the new facility project. This phase includes meetings with the board of directors, senior facility leadership, architect, and community representatives.
\end{abstract}


"It's hard to plan for the next 40-50 years using today's mindset!" Richard Azar, Chief Operating Officer, UCLA Medical Center

\section{The Design Phase}

During this phase, the architects complete the schematic design concept and the design development documents. Negotiations occur to finalize space validation for program management and operational needs. The building is designed based on national and state guidelines and project requirements that were developed during the planning phase. This phase includes meetings with senior leadership and key stakeholders to ensure requirements are understood, prioritized, and delegated to the appropriate resources.

\section{The Construction Phase}

0 During the construction phase, the facility engages a contractor who along with subcontractors will build the new facility according to the architectural plans and requirements. At this time the procurement process for equipment, furniture, IT systems, and various consultants such as the Transition and Activation planners are completed. This phase includes regular meetings with the Owner, Architect, and Construction (OAC) team and senior leadership to obtain updates about project estimates, including schedule, cost, and resources required.

The construction phase will vary based on the construction manager, the construction crew, the weather, and regulatory issues.

\section{The Transition Planning Phase}

This phase occurs in parallel with the construction of the new facility. It includes engaging stakeholders to plan and validate 
facility readiness, people readiness, and documentation readiness for the new facility. This phase begins approximately two years before Day 1 Activation. Outputs of the Transition Phase include facility resource identification, development of the Transition and Activation Budget, Transition and Activation Planning timeline and schedule, new operational plans and workflows, equipment and system procurement, orientation and training plan, fit-up plan, communication plan, regulatory plan, and move plan. This phase also involves regular meetings with the construction project team and leaders from within the organization.

The Transition Phase begins approximately two years before Day 1 Activation. The timeline is adjusted based on scope and complexity.

\section{The Activation Phase}

During the Activation Phase the focus changes from "planning" to "doing." This phase begins six to eight months before the move and activation and is where the building is transformed from a construction project to a live, interactive healthcare facility. This phase actively engages the end-users in the implementation and execution of the various plans developed during the Transition Phase. There is a ramp-up period that involves careful logistics planning to ensure that the appropriate people have access to the building at the right time and that the right resources are available to complete this work. This is the busiest time of the project for the owner and requires additional, dedicated full-time resources to support the activation of the new facility.

The Activation Phase is six to eight months before the move and is the busiest time for the internal hospital team as they transform the building into a live hospital. Full-time resources are required to support Day 1 Activation. 


\title{
The Stabilization Phase
}

\begin{abstract}
This phase includes the immediate postmove activities and lasts three to six months. The facility focuses on stabilizing ongoing operating procedures, refresh and focused orientation and training, facility issue management, and project closeout. The facility is fully operational, the construction project team closes out the project, and the owner is responsible for day-to-day operations.
\end{abstract}

\section{OVERVIEW OF CHAPTER CONTENT}

Chapter 1: Project Kickoff and Getting Started by Kelly Guzman, MN, RN, LBBP

This chapter focuses on the components and resources required for a successful project kickoff.

\section{Chapter 2: Tools for Success}

by Kelly Guzman, MN, RN, LBBP and Christina Olivarria, MSPM, LBBP

This chapter provides an overview of tools for consideration for the project management of a Transition and Activation Planning project.

\section{Chapter 3: New Facility Transition Budget Planning} by Jeff Agner, MPH, LBBP

This chapter describes the process for developing a Transition and Activation Budget. It includes the categorization of typical transition costs that are not included in the project budget, capital budget, or operations budget.

\section{Chapter 4: Building Readiness}

by Kathy Stevenson, BSN, RN, LBBP

This chapter details the critical importance of being prepared for building turnover and how to get the building ready for Day 1 Activation. 
Chapter 5: People Readiness

by Lynn Aguilera DM/IST, MSNEd, RN, CPN, PMP

This chapter reviews the human element of Transition and Activation Planning. It describes the required components to prepare the teams to work in their new environment. This includes culture, change management, team structure, workflow planning, and orientation and training.

Chapter 6: Reflections and Conclusions by Kelly Guzman, MN, RN, LBBP

This chapter proposes additional Transition and Activation-related activities for consideration when activating a new facility. 